\title{
NMDA Receptors with Locked Glutamate-Binding Clefts Open with High Efficacy
}

\author{
Cassandra L. Kussius and Gabriela K. Popescu \\ Department of Biochemistry, University at Buffalo, State University of New York, Buffalo, New York 14214
}

Glutamate-gated channels mediate fundamental brain processes, yet the mechanisms by which the neurotransmitter controls channel activation are incompletely understood. Structural studies revealed that the agonist has the critical role of bridging the divide between two flexible extracellular lobes and solidified the view that agonist-induced cleft-closure drives further isomerizations, which eventually open the channel. Within the glutamate receptor family, NMDA-sensitive channels are unique in their requirement that both glycine and glutamate bind to homologous regions on GluN1 and GluN2 subunits, respectively, before the channel can open. To study the gating reaction in separation from agonist binding and dissociation, we characterized the kinetic mechanism of individual NMDA receptors whose ligand-binding clefts were locked shut by disulfide bridges engineered across lobes. We found that locking GluN1 domains had no observable consequences on receptor activity, whereas locking GluN2A domains increased channel activity without reducing the number of resolvable kinetic states. Based on these results, we suggest that glutamate but not glycine activates NMDA receptors with submaximal efficacy. Low glutamate efficacy may represent a mechanism by which the neurotransmitter maintains control over receptor kinetics despite sharing with glycine the task of activation.

\section{Introduction}

Knowledge about the activation mechanism of ionotropic glutamate receptors (iGluRs) emanates principally from two still separate perspectives: structural studies of mostly inert receptor fragments (Madden, 2002; Gouaux, 2004; Mayer, 2006) and statistical evaluations of signals recorded from highly dynamic receptors (Erreger et al., 2004; Wollmuth and Sobolevsky, 2004). The absence of a unified model of how individual moving parts contribute to the electrical signal generated by a full receptor hampers our understanding of central synaptic transmission. All iGluRs are tetramers of homologous subunits whose extracellular portions are each organized as two stacked globular domains: an N-terminal, largely modulatory, domain; and a membraneproximal ligand-binding domain (LBD). The three-dimensional illustration of an electrically silent tetrameric receptor reveals multiple interactions among the eight extracellular modules but does not divulge the process by which resting receptors become active (Sobolevsky et al., 2009). Current hypotheses on receptor activation emerged from studies with isolated ligand-binding domains (Armstrong et al., 1998; Armstrong and Gouaux, 2000; Madden, 2002).

When studied in isolation, the two hinged lobes of an LBD adopt structures that are consistently more open for the apo- and antagonist-bound forms than for the agonist-bound complexes, and the degree of closure induced by a bound ligand corre-

Received June 28, 2010; revised July 29, 2010; accepted Aug. 2, 2010.

The work was supported financially by the National Institutes of Health (Grants NS0052669 and DA0024795 to G.K.P.). We thank Barbara Bistram, Jason Myers, and Eileen Kasperek for technical support. C.L.K. recorded and analyzed current traces. C.L.K. and G.K.P. designed the experiments, interpreted the results, and wrote the paper.

Correspondence should be addressed to Gabriela K. Popescu, Department of Biochemistry, School of Medicine and Biomedical Sciences, University at Buffalo, Buffalo, NY 14214. E-mail: popescu@buffalo.edu.

D01:10.1523/JNEUROSCI.3337-10.2010

Copyright $\odot 2010$ the authors $\quad 0270-6474 / 10 / 3012474-06 \$ 15.00 / 0$ lates with the efficacy of the respective ligand (Armstrong and Gouaux, 2000; Jin et al., 2003; Gouaux, 2004). It is currently supposed that receptor activation starts with agonist binding to open-cleft receptors, a process during which the ligand leaves the bulk solvent, associates noncovalently with receptor residues lining the inner surface of the upper lobe, and transforms apo receptors into docked receptors (supplemental Fig. S1 $a$, available at www.jneurosci.org as supplemental material). Next, the docked agonist establishes connections with residues on the opposite lobe facilitating additional cross-cleft interactions, which further stabilize the closed-cleft conformation and in effect physically trap the ligand (Abele et al., 2000; Cheng et al., 2005; Fenwick and Oswald, 2010). Presumably, the closed-cleft conformation is quasi-stable, and the structure can rearrange into active or desensitized conformations (Wollmuth and Sobolevsky, 2004). Still unknown is whether in full-length receptors the extent of cleftclosure stabilized by ligands is similar to that measured in isolated domains.

Among iGluRs, NMDA receptors (NMDARs) are particularly suited for functional studies because they have relatively slow kinetics, have large and uniform single-channel conductance, and display moderate desensitization (Cull-Candy et al., 2001). In addition, NMDARs are obligate heterotetramers of two glycine-binding GluN1 and two glutamate-binding GluN2 subunits, which makes it possible to separate subunit-specific contributions (Banke and Traynelis, 2003). During activation, fully liganded NMDARs transit through several electrically silent but thermodynamically resolvable states before accessing active conformations (supplemental Fig. S1b, available at www.jneurosci. org as supplemental material) (Banke and Traynelis, 2003; Popescu and Auerbach, 2003; Erreger et al., 2004). It is unknown which, if any, of these transitions correspond to the agonist-induced cleft-closure postulated by structural studies. 

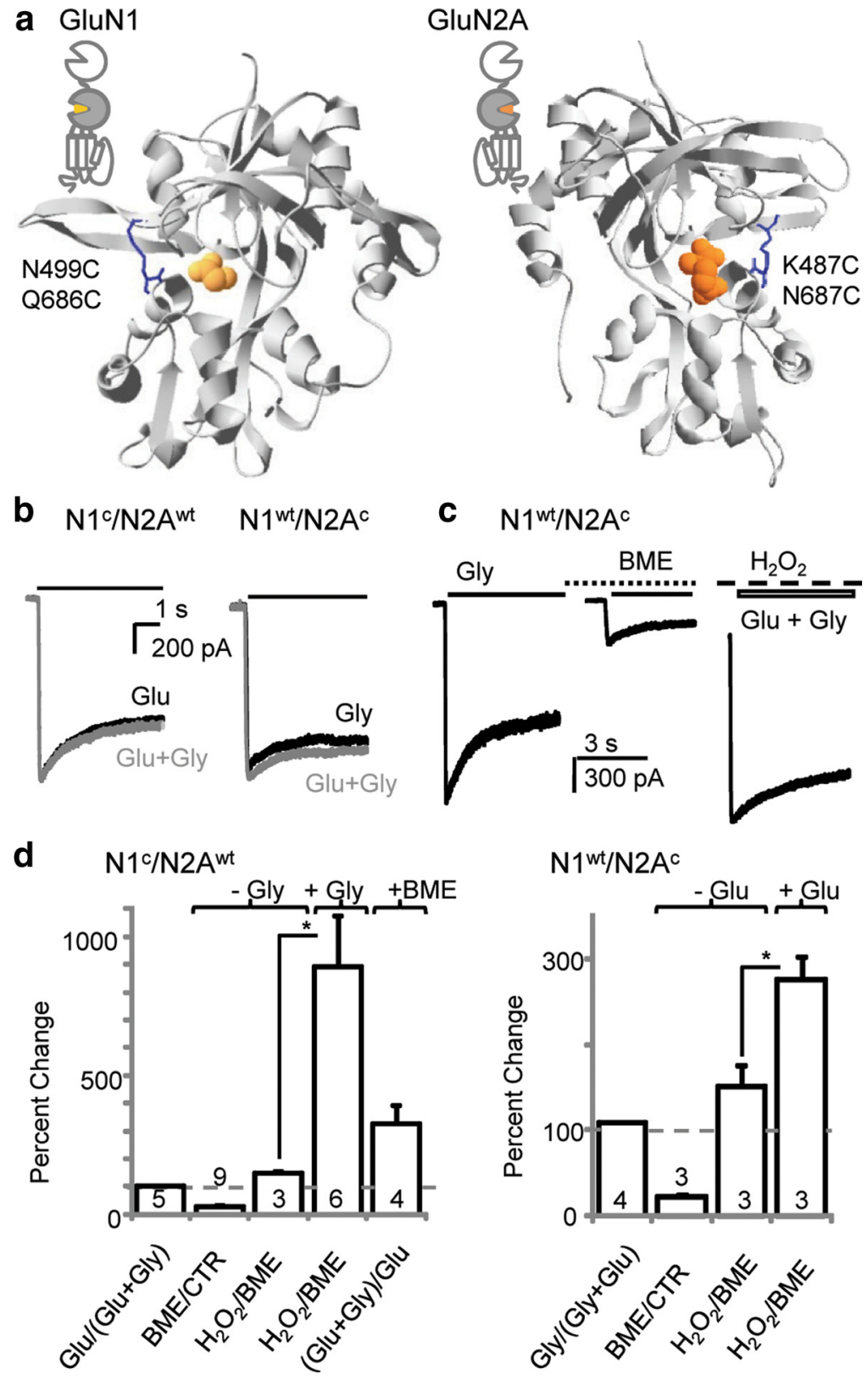

Figure 1. NMDARs with locked LBDs are functional. $a$, Structural models of GluN1-LBD in complex with glycine (yellow) (1PB7) and of GluN2A-LBD in complex with glutamate (orange) (2A5S) predict that cysteine residues engineered across clefts (blue) at positions N499 and Q686 in GluN1 (left) and K487 and N487 in GluN2A (right) are in sufficient proximity to interact to stabilize closed-cleft conformations. $\boldsymbol{b}, \boldsymbol{c}$, Whole-cell currents recorded during $5 \mathrm{~s}$ applications of Gly only or Gly and Glu (b), as indicated, and during reduction (c) (BME, $50 \mathrm{~mm}) /$ oxidation $\left(\mathrm{H}_{2} \mathrm{O}_{2}, 0.1 \%\right)$ cycles. $\boldsymbol{d}$, Summary of macroscopic experiments, bars are means $\pm \mathrm{SEM}, n$ is number of cells. ${ }^{*} p<0.05$.

To tease out the contribution of LBD lobe movements to NMDAR gating, we investigated single-channel behaviors of receptors whose ligand-binding domains were immobilized closed by disulfide bridges between cysteine residues engineered across ligand-binding clefts.

\section{Materials and Methods}

Rat GluN1-1a (U08261) and GluN2A (M91561) were each subcloned into pcDNA3.1 $(+)$. We used glycine-bound GluN1-LBD (1PB7) and glutamatebound GluN2A-LBD (2A5S) structural models to identify proximal residues across the cleft that may interact within the rigid LBD structure (Fig. 1a). Pairs of cysteines were substituted for N499 and Q686 in GluN1 (GluN1 ${ }^{\mathrm{c}}$ ) and for K487 and N687 in GluN2A (GluN2A ${ }^{c}$ ). These and green fluorescent protein (1:1:1) were transiently transfected into HEK293 cells (CRL-1573, ATCC). Measurements were made $12-48 \mathrm{~h}$ post-transfection.
Whole-cell recordings were performed in intracellular solutions containing the following (in mM): $135 \mathrm{CsF}, 33 \mathrm{CsOH}, 2 \mathrm{MgCl}_{2}, 1 \mathrm{CaCl}_{2}$, 10 HEPES, and 11 EGTA, adjusted to $\mathrm{pH} 7.4$ $(\mathrm{CsOH})$. Extracellular solutions contained (in mм) $150 \mathrm{NaCl}, 2.5 \mathrm{KCl}, 0.5 \mathrm{CaCl}_{2}, 0.01 \mathrm{EDTA}$, and $10 \mathrm{~N}$-(2-hydroxyethyl) piperazine- $\mathrm{N}$-(4butanesulfonic acid) (HEPBS), adjusted to $\mathrm{pH}$ $8(\mathrm{NaOH})$, and agonists contained $1 \mathrm{~mm}$ Glu and $0.1 \mathrm{~mm}$ Gly, and were applied with a focal perfusion pencil (Automate Scientific) attached to an eight-valve pressurized solution exchange system (BPS-8, ALA Scientific). After amplification and filtering at $2 \mathrm{kHz}$ (Axopatch 200B; 4-pole Bessel, Molecular Devices), currents were sampled at $5 \mathrm{kHz}$ (Digidata 1322A, Molecular Devices) and acquired and analyzed with pCLAMP 8.2. Disulfide bonds were reduced or oxidized with $50 \mathrm{~mm}$ BME or $0.1 \%$ $\mathrm{H}_{2} \mathrm{O}_{2}$, respectively.

Single-channel recordings were obtained in the cell-attached patch-clamp configuration. Electrodes were filled with the following (in $\mathrm{mm}$ ): $150 \mathrm{NaCl}, 2.5 \mathrm{KCl}, 1$ EDTA, 10 HEPBS, $\mathrm{pH} 8(\mathrm{NaOH})$, and agonists, as indicated. Currents were amplified, low-pass filtered (10 $\mathrm{kHz}$ ), and sampled at $40 \mathrm{kHz}$ (Axopatch 200B, Molecular Devices; PCI-6229, National Instruments). All data were acquired and analyzed with QuB software. Only records with one active receptor were selected for analyses. Processing was minimal, to correct drifting baselines and occasional high-frequency spikes. Modeling was performed with the MIL algorithm on digitally filtered data (12 $\mathrm{kHz}$ ) with $0.15 \mathrm{~ms}$ dead-time. Best fits were determined individually for each record by adding $\mathrm{C}$ and $\mathrm{O}$ states sequentially, using a log-likelihood threshold of 10 units. Results are given as the mean \pm SEM; differences were considered significant for $p$ values $<0.05$ in the unpaired Student's $t$ tests.

\section{Results}

Pairs of engineered cysteine residues lock receptors in closed-cleft conformations

The activation reaction of neurotransmittergated channels is commonly investigated with statistical analyses of single-channel currents. In these studies, gating transitions can be examined separately from agonist association and dissociation steps, for example by recording activity in the presence of high concentrations of agonists, when rebinding occurs faster than can be experimentally detected, and thus renders these events invisible (Popescu and Auerbach, 2003; Popescu et al., 2004). Because, even though undetectably fast, agonist rebinding occurs repeatedly during stationary gating, both the docked and the locked LBD conformations are visited frequently and must represent, or at least be a part of, one of the three closed components identified within clusters of activity. To estimate the impact of LBD mobility on the gating reaction, we prevented transitions into opencleft conformations by engineering covalent cross-links across LBD clefts.

Using published structural models of agonist-bound soluble LBDs of GluN1 and GluN2A (Furukawa and Gouaux, 2003; Fu- 
rukawa et al., 2005; Inanobe et al., 2005), we selected and replaced the N499/Q686 pair in GluN1 and the K487/N687 pair in GluN2A with cysteine residues to produce GluN $1^{c}$ and GluN2A ${ }^{c}$, respectively. These substitutions predicted in silico spontaneous disulfide bond formation within the static crystal structures (Fig. 1a), consistent with the assumption that cross-linking will constrain the LBDs in conformations that closely resemble those proposed for soluble LBDs.

Engineered receptors are functional We tested the functionality of the engineered subunits by expressing GluN $1{ }^{\mathrm{c}}$ or GluN2A ${ }^{c}$ in HEK293 cells, together with the required wild-type pair, GluN2 $\mathrm{A}^{\mathrm{wt}}$ or GluN1 ${ }^{\text {wt }}$, respectively, and measuring agonist-induced currents. Consistent with previous reports, receptors with cleft-spanning disulfide bonds were constitutively active with respect to the cognate agonist (Blanke and VanDongen, 2008). Thus, we were able to elicit activity from GluN1\%GluN2A ${ }^{\mathrm{wt}}\left(\mathrm{N} 1^{\mathrm{c}} / \mathrm{N} 2 \mathrm{~A}^{\mathrm{wt}}\right)$ receptors by applying glutamate as the only agonist, and from GluN1 $1^{\text {wt }}$ GluN2 $\mathrm{A}^{\mathrm{c}}\left(\mathrm{N} 1^{\mathrm{wt}} / \mathrm{N} 2 \mathrm{~A}^{\mathrm{c}}\right)$ receptors by applying only glycine. For both receptors, currents elicited with both agonists were only marginally, if at all, larger (Fig. 1b).

Further, whole-cell responses recorded under reducing conditions (BME, $50 \mathrm{~mm}$ ) eliminated $74 \%$ of the activity elicited by glutamate from $\mathrm{N} 1^{\mathrm{c}} / \mathrm{N} 2 \mathrm{~A}^{\mathrm{wt}}$ receptors. Residual currents represented most likely incomplete disulfide bond reduction, since reoxidation $\left(\mathrm{H}_{2} \mathrm{O}_{2}, 0.1 \%\right)$ in the presence of both agonists restored full activity (Fig. 1c). Cells expressing $\mathrm{N}^{\mathrm{wt}}$ / $\mathrm{N} 2 \mathrm{~A}^{\mathrm{c}}$ receptors exhibited similar behaviors (Fig. 1d). Based on these results, we concluded that engineered receptors reached the cell membrane in oxidized states and were constitutively active. Next, we proceeded to characterize the single-channel kinetics of locked cleft receptors.

\section{Cleft opening makes minor contributions to stationary gating kinetics}

We recorded current traces from cell-attached patches containing only one active receptor, with glutamate $(1 \mathrm{~mm})$ from $\mathrm{N}^{\mathrm{c}} \%$ $\mathrm{N}_{2} \mathrm{~A}^{\mathrm{wt}}(n=11)$; with glycine $(0.1 \mathrm{mM})$ from $\mathrm{N} 1{ }^{\mathrm{wt}} / \mathrm{N}^{\mathrm{c}} \mathrm{A}^{\mathrm{c}}(n=8)$; or in the absence of added agonists from $\mathrm{N} 1{ }^{c} / \mathrm{N} 2 \mathrm{~A}^{\mathrm{c}}(n=6)$. We compared these traces with activity recorded with both agonists from wild-type receptors (wt) $(n=10)$ (Fig. 2).

Open probabilities $\left(\mathrm{P}_{\mathrm{o}}\right)$ of $\mathrm{N}^{\mathrm{c}} / \mathrm{N} 2 \mathrm{~A}^{\mathrm{wt}}$ receptors were indistinguishable from those of $\mathrm{N} 1{ }^{\mathrm{wt}} / \mathrm{N} 2 \mathrm{~A}^{\mathrm{wt}}$ receptors $(0.57 \pm 0.05 \mathrm{vs}$ $0.54 \pm 0.05, p>0.7)$. Similarly, the single-channel $\mathrm{P}_{\mathrm{o}}$ of $\mathrm{N} 1{ }^{\mathrm{wt}} /$ $\mathrm{N} 2 \mathrm{~A}^{\mathrm{c}}$ receptors was not statistically different from that of $\mathrm{N} 1 \%$ $\mathrm{N}^{2} \mathrm{~A}^{\mathrm{c}}$ receptors $(0.69 \pm 0.04$ vs $0.64 \pm 0.06, p>0.4)$, indicating that glycine binding and covalent GluN1 cleft closure opened the channel with similar efficacies. In contrast, whether the receptors contained GluN1 ${ }^{\text {wt }}$ or GluN1 ${ }^{\mathrm{c}}$, cross-linking the GluN2A pocket resulted in $18 \%$ higher intracluster $\mathrm{P}_{\mathrm{o}}$ compared with glutamate-

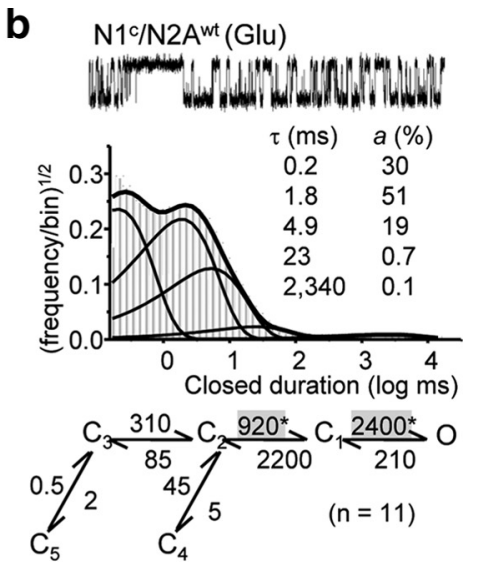

d

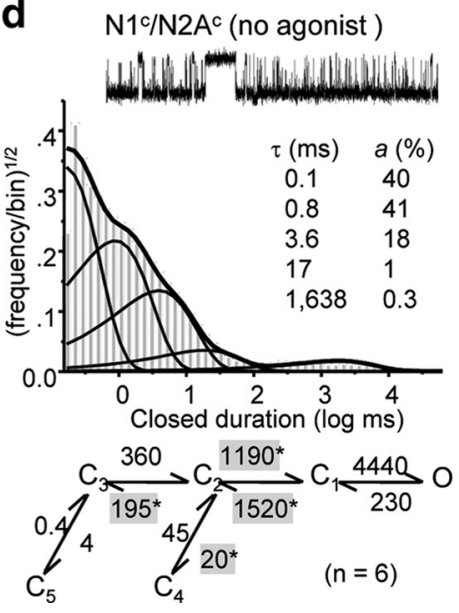

Figure 2. Kinetic behaviors of single NMDARs. $\boldsymbol{a}-\boldsymbol{d}$, Cell-attached currents recorded from cells expressing N1 ${ }^{\mathrm{wt}} / \mathrm{N} 2 \mathrm{~A}^{\mathrm{wt}}(\boldsymbol{a})$, (b), N1 ${ }^{\mathrm{wt}} / \mathrm{N} 2 \mathrm{~A}^{\mathrm{C}}(\boldsymbol{c})$, and $\mathrm{N} 1{ }^{\mathrm{C}} / \mathrm{N} 2 \mathrm{~A}^{\mathrm{C}}(\boldsymbol{d})$. Top, $500 \mathrm{~ms}$ current trace from a one-channel patch; histograms of closed(thick lines) calculated from $5 \mathrm{C} 10$ kinetic models; inset, time constants $(\tau)$ and relative areas (a) for the components shown; kinetic model with the means of optimized rate constants $\left(s^{-1}\right){ }^{*} p<0.05$.

elicited clusters $(0.85 \pm 0.02$ vs $0.72 \pm 0.03, p<0.014)$ (Table 1 ). These results indicate that when compared with glutamate binding covalent GluN2A cleft closure is a more efficacious means of opening the channel.

Engineered receptors had wild-type gating mechanisms as assessed by the number of closed and open components discerned in the single-channel record. Mean open durations and open interval distributions were similar for all the channels tested (Table 1; supplemental Table 1, available at www.jneurosci.org as supplemental material). The number of closed components, $\mathrm{E}_{1}-\mathrm{E}_{5}$ was also similar, and intracluster components $\mathrm{E}_{1}-\mathrm{E}_{3}$ comprised $>98 \%$ of all closures in all records (Fig. 2; supplemental Table 2, available at www.jneurosci.org as supplemental material). Thus, preventing cleft opening did not reduce the number of open or closed kinetic states visited by receptors during stationary gating. This result represents strong evidence that none of the kinetic components identified by functional studies reflects exclusively sojourns into docked conformations (supplemental Fig. 1, available at www.jneurosci.org as supplemental material).

Inspecting the event duration distributions, we found that the higher $\mathrm{P}_{\mathrm{o}}$ of GluN2A ${ }^{\mathrm{C}}$ clusters resulted from smaller $\mathrm{E}_{3}$ area and shorter $\mathrm{E}_{2}$ and $\mathrm{E}_{3}$ closed components. Smaller $\mathrm{E}_{3}$ area is consistent with the possibility that docked conformations, denied to locked cleft receptors, represent a fraction of this longer intracluster closed component (supplemental Table 2, available at 
Table 1. Single-channel properties of locked LBD mutants

\begin{tabular}{|c|c|c|c|c|c|c|}
\hline & $n$ & Events & $\mathrm{P}_{0}$ entire record ${ }^{a}$ & $P_{0}$ clusters $^{b}$ & MOT (ms) & MCT (ms) \\
\hline $\mathrm{N} 1^{\mathrm{wt}} / \mathrm{N} 2 \mathrm{~A}^{\mathrm{wt}}$ & 10 & $3.0 \times 10^{6}$ & $0.54 \pm 0.04$ & $0.72 \pm 0.03$ & $6.9 \pm 0.7$ & $6.0 \pm 0.8$ \\
\hline $\mathrm{N} 1{ }^{\mathrm{C}} / \mathrm{N} 2 \mathrm{~A}^{\mathrm{wt}}$ & 11 & $3.7 \times 10^{6}$ & $0.57 \pm 0.05$ & $0.72 \pm 0.03$ & $6.5 \pm 0.6$ & $5.2 \pm 0.7$ \\
\hline $\mathrm{N} 1^{\mathrm{wt}} / \mathrm{N} 2 \mathrm{~A}^{\mathrm{c}}$ & 8 & $4.1 \times 10^{6}$ & $0.69 \pm 0.04^{*}$ & $0.85 \pm 0.02^{*}$ & $7.6 \pm 0.8$ & $3.4 \pm 0.7^{*}$ \\
\hline $\mathrm{N} 1^{\mathrm{C}} / \mathrm{N} 2 \mathrm{~A}^{\mathrm{C}}$ & 6 & $2.3 \times 10^{6}$ & $0.64 \pm 0.06$ & $0.85 \pm 0.02^{*}$ & $6.9 \pm 1.5$ & $6.3 \pm 1.1$ \\
\hline
\end{tabular}

${ }^{*} p<0.05$, compared to $\mathrm{N} 1{ }^{\mathrm{wt}} / \mathrm{N} 2 \mathrm{~A}{ }^{\mathrm{wt}}$. MOT, Mean open time; MCT, mean closed time.

${ }^{a}$ Calculated as the sum of fractional open-state occupancies from a 5 C30 kinetic model fitted to the data in each record, and averaged for each condition.

${ }^{b}$ Calculated from the same 5 C30 model, after omitting desensitization (states $C_{4}$ and $C_{5}$ ).

www.jneurosci.org as supplemental material). Shorter $\mathrm{E}_{2}$ and $\mathrm{E}_{3}$ components may be indicative of submaximal glutamate efficacy at GluN2A-containing receptors (Kussius and Popescu, 2009; Kussius et al., 2010). To investigate this new lead, we next quantified the gating reaction of receptors with cross-linked LBDs.

\section{Glutamate has submaximal efficacy at GluN1/GluN2A receptors}

As expected from the event duration distributions, all singlechannel traces analyzed were best approximated by kinetic models having five closed and four open states (5C4O) (Fig. 2; supplemental Tables 1, 2, available at www.jneurosci.org as supplemental material). This result is consistent with a $5 \mathrm{C} 2 \mathrm{O}$ fundamental gating mechanism (Banke and Traynelis, 2003; Erreger et al., 2005) superimposed with three gating modes (Popescu and Auerbach, 2003; Amico-Ruvio and Popescu, 2010).

For GluN1/GluN2A receptors, the five closed components are similar regardless of mode, whereas the longer of the two open components is mode specific. For this reason, in records that include modal gating, open distributions are more complex. For simplicity, we chose to represent all openings as a single compound state, with the caveat that estimated rate constants for transitions into and from this aggregate state will represent averages of several unitary reactions. However, because the two open states in each mode are coupled and distal to binding transitions, and in our datasets openings were largely unaffected, this simplification should not diminish our ability to estimate accurately all the other transitions postulated in the model (Popescu and Auerbach, 2003; Kussius et al., 2010).

Using the 5C1O model, we found that locking the GluN1 cleft produced activations very similar to those produced by glycine binding, with only small changes in the rate constants for the consecutive $\mathrm{C}_{2} \rightarrow \mathrm{C}_{1} \rightarrow \mathrm{O}$ transitions $(p<0.004)$. Moreover, these two changes were of opposite signs and had no impact on the overall $\mathrm{P}_{\mathrm{o}}$ (Fig. 2, Table 1). In contrast, when we compared receptors activated by locking the GluN2 cleft with those activated by glutamate-binding $\left(\mathrm{N} 1^{\mathrm{wt}} / \mathrm{N} 2 \mathrm{~A}^{\mathrm{c}}\right.$ and $\mathrm{N} 1^{\mathrm{c}} / \mathrm{N} 2 \mathrm{~A}^{\mathrm{c}}$ vs $\mathrm{N} 1^{\mathrm{wt}} / \mathrm{N} 2 \mathrm{~A}^{\mathrm{wt}}$, and $\mathrm{N} 1^{\mathrm{c}} / \mathrm{N} 2 \mathrm{~A}^{\mathrm{wt}}$, respectively), several rate constants were substantially different: $\mathrm{k}_{32}, \mathrm{k}_{23}, \mathrm{k}_{24}, \mathrm{k}_{21}$, and $\mathrm{k}_{12}(p<$ 0.04 ) (Fig. 2; supplemental Table 3, available at www.jneurosci. org as supplemental material). The pattern of change was similar but of opposite direction to that described for partial agonists (Kussius and Popescu, 2009; Dravid et al., 2010; Kussius et al., 2010). These results support the view that glutamate elicits submaximal activity from NMDARs by a mechanism similar to other glutamate-site agonists, and thus it may display only partial agonism.

\section{GluN1 ${ }^{c}$ does not influence GluN2A affinity for glutamate} Several lines of evidence argue for extensive allosteric communication between ligand-binding domains within NMDARs. For example, glutamate binding causes a marked decrease in receptor affinity for glycine, a phenomenon initially described as glycinedependent desensitization (Mayer et al., 1989; Benveniste et al., 1990; Regalado et al., 2001). Conversely, the affinity for glutamate decreases upon binding glycine, although this effect is less obvious (Nahum-Levy et al., 2001). To discriminate whether the lower $\mathrm{P}_{\mathrm{o}}$ induced by glutamate when compared with covalent trapping reflected lower glutamate efficacy or a marked decrease in glutamate affinity caused by cross-linking the glycine-binding cleft, we quantified glutamate binding to $\mathrm{N}^{\mathrm{c}} / \mathrm{N} 2 \mathrm{~A}^{\mathrm{wt}}$ receptors.

We modeled the binding reactions as two sequential association steps attached to the closed state $\mathrm{C}_{3}$ of the $5 \mathrm{C} 1 \mathrm{O}$ model above and fitted this expanded model globally to single-channel traces recorded from $\mathrm{N} 1{ }^{\mathrm{c}} / \mathrm{N} 2 \mathrm{~A}^{\mathrm{wt}}$ receptors in the presence of $5,3,2$, and $1 \mu \mathrm{M}$ glutamate $(n=3$ for each condition) (supplemental Fig. 2, available at www.jneurosci.org as supplemental material). The estimated association/dissociation rate constants $k_{+}=1.4 \times$ $10^{7} \mathrm{M}^{-1} \mathrm{~s}^{-1}$ and $k_{-}=58 \mathrm{~s}^{-1}$ were very similar to those we reported previously for GluN1/GluN2A receptors (Popescu et al., 2004). In addition, the calculated binding equilibrium constant, $k_{\_} / k_{+}=4.2 \mu \mathrm{M}$, was very close to $\mathrm{EC}_{50}=2.3 \mu \mathrm{M}$ determined from either single-channel open probabilities or whole-cell currents (supplemental Fig. 2, available at www.jneurosci.org as supplemental material). Based on these results, we conclude that receptors with covalently locked GluN2A clefts have higher activities than glutamate-bound wild-type receptors entirely because of more efficacious gating.

\section{Discussion}

Current hypotheses about how agonists activate iGluRs emerged from meticulous examination of high-resolution structures obtained for isolated LBDs (Armstrong et al., 1998; Armstrong and Gouaux, 2000). Generally, apo- and antagonist-bound LBDs adopt open-cleft conformations, whereas agonist-bound forms have narrower clefts (Gouaux, 2004; Mayer, 2006). Except for GluN1-LBDs, which have fully closed-cleft structures regardless of the efficacy of the agonist occupying the binding pocket (Inanobe et al., 2005), most of the soluble agonist-bound LBDs characterized reveal a range of closed-cleft conformations, and the degree of cleft closure generally mirrors the efficacy of the bound agonist (Jin et al., 2003). Two questions remain unanswered: whether in intact iGluRs agonist-bound LBDs have the same degree of lobe closure as observed in isolated LBDs; and whether the graded cleft-closure mechanism also explains partial agonism at GluN1 subunits.

We addressed these issues by examining NMDARs whose ligand-binding pockets were locked shut by disulfide bridges engineered across lobes. Structural models of soluble GluN1- and GluN2A-LBDs predict that glycine and glutamate, respectively, stabilize closed-cleft conformations where pairs of residues situated on opposing lobes are brought within adequate proximity and orientation to interact spontaneously (Furukawa and Gouaux, 2003; Furukawa et al., 2005). We substituted cysteines at 


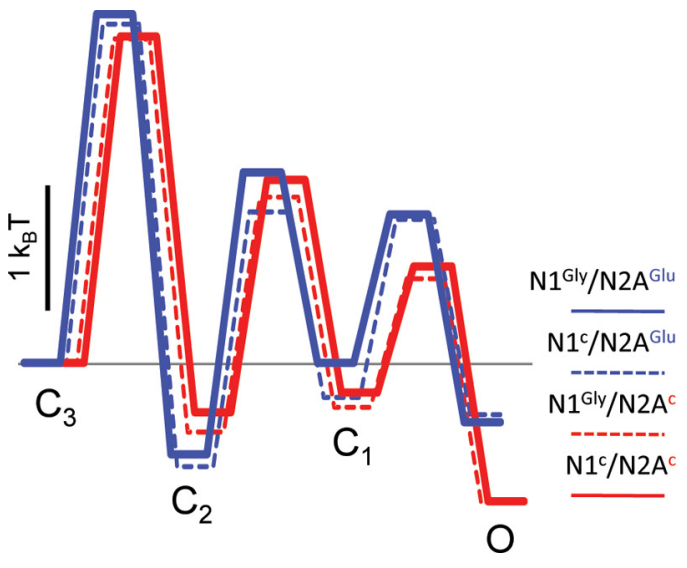

Figure 3. Glutamate activates NMDARs with low efficacy. Free-energy trajectories calculated for several receptor/agonist pairs from the kinetic models illustrated in Figure 2 plotted relative to the kinetic state $C_{3}$. Glycine (broken lines) or covalent locking of GluN1 cleft (solid lines) produced similar profiles regardless of how the paired subunit was activated. Active states of glutamate-bound receptors (blue) were less stable than those of receptors with locked GluN2A cleft (red), regardless of how the GluN1 subunit was activated.

the corresponding positions in full-length GluN1 (N499 and Q686) and GluN2 (K487 and N687) subunits assuming that, throughout the gating reaction, the resulting disulfide bond will juxtapose opposing lobes at fixed distances akin to those observed in soluble domains.

We were surprised to discover that glycine or cross-linking, but not glutamate, activated GluN1/GluN2A channels with highest efficacy. Relative to the activity measured from receptors with cross-linked lobes $\left(\mathrm{P}_{\mathrm{o}}=0.64,100 \%\right)$, glycine had full efficacy $\left(\mathrm{P}_{\mathrm{o}}=\right.$ $0.69,108 \%, p>0.05)$, whereas glutamate had only partial efficacy $\left(\mathrm{P}_{\mathrm{o}}=0.57,89 \%, p<0.05\right)$. Our results established that whether activated by agonist binding or by covalent cleft locking, GluN1/GluN2A receptors gate with similar mechanisms, as defined by the number of kinetic states detected in single-channel records. Based on this result, we conclude that none of the transitions postulated by the model represent cleft fluctuations of either the GluN1 or GluN2A LBDs, and we suggest that fluctuations of LBD lobes between open and closed positions contribute minimally to NMDAR stationary gating. However, because records from GluN2 $\mathrm{A}^{\mathrm{c}}$-containing receptors had fewer long closures within bursts $\left(a_{3}, 17\right.$ vs $\left.30 \%, p<0.5\right)$, it is possible that such motions represent a subset of the $\mathrm{C}_{3}$ state (supplemental Table 2, available at www.jneurosci.org as supplemental material). Alternatively, it is possible that ligand-induced lobe motions are integral to the binding reaction and thus contribute to NMDAR affinity (Cheng et al., 2005; Maier et al., 2007). However, depending on the activation method, we observed substantial difference in the relative energies of the conformers that populated the gating pathway indicative of differences in opening efficacy (Fig. 3).

Theoretically, two types of mechanisms can account for differences in efficacy, each having distinct thermodynamic signatures. In one, the ligand stabilizes the LBDs in conformations with only partially closed clefts, and this inadequate structure is maintained throughout the gating reaction. This mechanism will be reflected in all, or most, gating intermediates having higher free energies (Kussius and Popescu, 2009). The other possibility is that the ligand stabilizes conformations indistinguishable from those favored by full agonists but does so with lower probability. In this latter case, the initial agonist-dependent step occurs infrequently, but once the high-energy barrier is surmounted, the activation reaction follows a free-energy profile that is similar to that produced by the full agonist (Lape et al., 2008). Consistent with the first scenario, we found that, compared with locked-cleft receptors, glutamate produced a general redistribution of receptors across the observed kinetic states, toward species with higher free energies (Fig. 3).

Because the disulfide bonds were designed to lock receptors in conformations akin to those observed in soluble glutamatebound LBDs, one implication of these results is that in full-length NMDARs glutamate stabilizes conformations that are different, perhaps more open than in isolated domains. This proposal is consistent with the idea that in full-length receptors, but not in isolated LBDs, cleft closure occurs at the expense of rearrangements elsewhere in the protein, and thus the free energy contributed by ligand binding is not fully available for cleft closure. However, this may be a phenomenon specific to the highly coupled NMDARs and not necessarily a general mechanism in iGluRs. In this respect, it is interesting to note that the extent of protomer separation induced by glutamate within dimeric soluble LBDs was significantly smaller for GluN1-GluN2A dimers than for non-NMDA receptor dimers: 32 versus $38 \AA$, respectively (Furukawa et al., 2005). This effect was largely attributed to a smaller movement of the lower GluN2A lobe but not GluN1 lobe, an observation entirely consistent with the possibility that synthetic glutamate-site ligands can be designed that would promote further cleft closure and thus higher channel $\mathrm{P}_{\mathrm{o}}$.

We should note that, for several soluble LBDs of non-NMDA receptors, partial agonists stabilize structures with a similar degree of cleft closure as the full agonist but display twisted or distorted conformations that have been proposed to constitute the structural basis of partial efficacy at these receptor subtypes (Holm et al., 2005; Birdsey-Benson et al., 2010). Thus, it is also possible that the disulfide bonds we engineered favored an unnatural arrangement of the GluN2A lobes. Still, these results indicate strongly that it may be possible to design small ligands for this subunit that will activate the receptor with more efficacy than glutamate.

In contrast to the graded cleft closure induced by low-efficacy agonists in the LBDs of most non-NMDA receptor subunits, soluble GluN1-LBDs adopt structures with fully closed clefts whether the bound ligand is glycine or a partial agonist. This observation has called into question the conservation of partial agonist action among iGluRs (Inanobe et al., 2005). Our suggestion that in full-length NMDARs glutamate binding may stabilize cleft conformations that are more open than those stabilized in the corresponding detached LBDs also allows for the possibility that glycine-site partial agonists may stabilize conformations that are more open than those observed in the separated domain. Together with our previous observation that partial agonists at either GluN1 or GluN2 subunits have indistinguishable kinetic signatures and may act by a similar mechanism (Kussius and Popescu, 2009), these results are consistent with the hypothesis that graded cleft closure represents a general mechanism of partial agonism at iGluR subunits (Jin et al., 2003).

Although both glutamate and glycine appear to serve the identical mechanistic task of moving the lobes within their respective LBDs, only glutamate has the neurotransmitter role, whereas glycine plays a modulatory, even if essential, one. The possibility that the efficacy of glutamate is submaximal may be a mechanism by which the neurotransmitter controls the rate-limiting steps of gating and thus maintains the reigns over the activation kinetics of the channel, even after evolving the added functionality of requiring a coagonist. It may also represent the mechanism by which the developmentally and regionally regulated GluN2 sub- 
units exert more influence over the activation reaction than the "standard" GluN1 subunits. Perhaps, it is not accidental that GluN2 subunits are the ones setting the distinctive kinetic and pharmacological features of NMDARs.

In summary, our results support the graded cleft-closure hypothesis as a mechanism for partial agonism in intact NMDARs and imply that low-efficacy agonists may stabilize conformations that are more closed in isolated LBDs relative to full-length receptors. Thus, despite causing full cleft closure in isolated LBDs, glutamate may be a low-efficacy agonist for GluN1/GluN2A receptors, a feature that allows the physiologic neurotransmitter to control the kinetics of NMDAR activation. Physiologically, the low efficacy of glutamate may serve to leave room for both up and down modulation by synaptic effectors; pharmacologically, it opens the possibility of finding new drugs that act by themselves with full efficacy at the glutamate site or boost glutamate efficacy allosterically.

\section{References}

Abele R, Keinanen K, Madden DR (2000) Agonist-induced isomerization in a glutamate receptor ligand-binding domain. A kinetic and mutagenetic analysis. J Biol Chem 275:21355-21363.

Amico-Ruvio SA, Popescu GK (2010) Stationary gating of GluN1/GluN2B receptors in intact membrane patches. Biophys J 98:1160-1169.

Armstrong N, Gouaux E (2000) Mechanisms for activation and antagonism of an AMPA-sensitive glutamate receptor: crystal structures of the GluR2 ligand binding core. Neuron 28:165-181.

Armstrong N, Sun Y, Chen GQ, Gouaux E (1998) Structure of a glutamatereceptor ligand-binding core in complex with kainate. Nature 395:913917.

Banke TG, Traynelis SF (2003) Activation of NR1/NR2B NMDA receptors. Nat Neurosci 6:144-152.

Benveniste M, Clements J, Vyklický L Jr, Mayer ML (1990) A kinetic analysis of the modulation of N-methyl-D-aspartic acid receptors by glycine in mouse cultured hippocampal neurones. J Physiol 428:333-357.

Birdsey-Benson A, Gill A, Henderson LP, Madden DR (2010) Enhanced efficacy without further cleft closure: reevaluating twist as a source of agonist efficacy in AMPA receptors. J Neurosci 30:1463-1470.

Blanke ML, VanDongen AM (2008) Constitutive activation of the N-methylD-aspartate receptor via cleft-spanning disulfide bonds. J Biol Chem 283:21519-21529.

Cheng Q, Du M, Ramanoudjame G, Jayaraman V (2005) Evolution of glutamate interactions during binding to a glutamate receptor. Nat Chem Biol 1:329-332.

Cull-Candy S, Brickley S, Farrant M (2001) NMDA receptor subunits: diversity, development and disease. Curr Opin Neurobiol 11:327-335.

Dravid SM, Burger PB, Prakash A, Geballe MT, Yadav R, Le P, Vellano K, Snyder JP, Traynelis SF (2010) Structural determinants of D-cycloserine efficacy at the NR1/NR2C NMDA receptors. J Neurosci 30:2741-2754.

Erreger K, Geballe MT, Dravid SM, Snyder JP, Wyllie DJ, Traynelis SF (2005)
Mechanism of partial agonism at NMDA receptors for a conformationally restricted glutamate analog. J Neurosci 25:7858-7866.

Erreger K, Chen PE, Wyllie DJ, Traynelis SF (2004) Glutamate receptor gating. Crit Rev Neurobiol 16:187-224.

Fenwick MK, Oswald RE (2010) On the mechanisms of alpha-amino-3hydroxy-5-methylisoxazole-4-propionic acid (AMPA) receptor binding to glutamate and kainate. J Biol Chem 285:12334-12343.

Furukawa H, Gouaux E (2003) Mechanisms of activation, inhibition and specificity: crystal structures of the NMDA receptor NR1 ligand-binding core. EMBO J 22:2873-2885.

Furukawa H, Singh SK, Mancusso R, Gouaux E (2005) Subunit arrangement and function in NMDA receptors. Nature 438:185-192.

Gouaux E (2004) Structure and function of AMPA receptors. J Physiol 554:249-253.

Holm MM, Lunn ML, Traynelis SF, Kastrup JS, Egebjerg J (2005) Structural determinants of agonist-specific kinetics at GluR2. Proc Natl Acad Sci U S A 102:12053-12058.

Inanobe A, Furukawa H, Gouaux E (2005) Mechanism of partial agonist action at the NR1 subunit of NMDA receptors. Neuron 47:71-84.

Jin R, Banke TG, Mayer ML, Traynelis SF, Gouaux E (2003) Structural basis for partial agonist action at ionotropic glutamate receptors. Nat Neurosci 6:803-810.

Kussius CL, Popescu AM, Popescu GK (2010) Agonist-specific gating of NMDA receptors. Channels (Austin) 4:78-82.

Kussius CL, Popescu GK (2009) Kinetic basis of partial agonism at NMDA receptors. Nat Neurosci 12:1114-1120.

Lape R, Colquhoun D, Sivilotti LG (2008) On the nature of partial agonism in the nicotinic receptor superfamily. Nature 454:722-727.

Madden DR (2002) The structure and function of glutamate receptor ion channels. Nat Rev Neurosci 3:91-101.

Maier W, Schemm R, Grewer C, Laube B (2007) Disruption of interdomain interactions in the glutamate binding pocket affects differentially agonist affinity and efficacy of N-methyl-D-aspartate receptor activation. J Biol Chem 282:1863-1872.

Mayer ML (2006) Glutamate receptors at atomic resolution. Nature 440:456-462.

Mayer ML, Vyklicky L Jr, Clements J (1989) Regulation of NMDA receptor desensitization in mouse hippocampal neurons by glycine. Nature 338:425-427.

Nahum-Levy R, Lipinski D, Shavit S, Benveniste M (2001) Desensitization of NMDA receptor channels is modulated by glutamate agonists. Biophys J 80:2152-2166.

Popescu G, Auerbach A (2003) Modal gating of NMDA receptors and the shape of their synaptic response. Nat Neurosci 6:476-483.

Popescu G, Robert A, Howe JR, Auerbach A (2004) Reaction mechanism determines NMDA receptor response to repetitive stimulation. Nature 430:790-793.

Regalado MP, Villarroel A, Lerma J (2001) Intersubunit cooperativity in the NMDA receptor. Neuron 32:1085-1096.

Sobolevsky AI, Rosconi MP, Gouaux E (2009) X-ray structure, symmetry and mechanism of an AMPA-subtype glutamate receptor. Nature 462:745-756

Wollmuth LP, Sobolevsky AI (2004) Structure and gating of the glutamate receptor ion channel. Trends Neurosci 27:321-328. 